Review

\title{
EnergyPlus-Towards the Selection of Right Simulation Tool for Building Energy and Power Systems Research
}

\author{
Syed Ali Muslim * \\ University of Calgary, Canada; E-Mail: ali.syed5@ucalgary.ca \\ * Correspondence: Syed Ali Muslim; E-Mail: ali.syed5@ucalgary.ca
}

Academic Editor: Mohammad Jafari

Special Issue: Optimal Energy Management and Control of Renewable Energy Systems

\author{
Journal of Energy and Power Technology \\ Received: February 05, 2021 \\ 2021, volume 3 , issue 3 \\ Accepted: May 19, 2021 \\ doi:10.21926/jept.2103034 \\ Published: July 19, 2021
}

\begin{abstract}
This article offers the summary of detailed literature review on the state of the art of simulation tools for building energy and power system research. The fundamental capabilities required for building energy and power system analysis tools are outlined. A comparative review of different energy simulation tools is presented, along with the summary of their strengths and weaknesses. A review of energy simulation tool rankings using evidence-based research is presented. A novel aspect of this article is the investigation of the limitations of energy simulation tools for district level energy analysis. A state of the art review of the cosimulation platforms to overcome technical difficulties of multi-domain energy and power systems used for district level energy analysis is presented. This article offering a review of latest developments in the building energy and power system simulation tools to help researchers and industry professional to choose the right platform for building energy and power system design and analysis.
\end{abstract}

\section{Keywords}

Energy modelling; energy simulation; building energy management

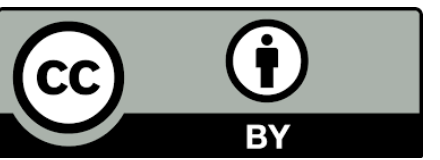

(C) 2021 by the author. This is an open access article distributed under the conditions of the Creative Commons by Attribution License, which permits unrestricted use, distribution, and reproduction in any medium or format, provided the original work is correctly cited. 


\section{Introduction}

Energy simulation tools facilitate investigation of new ideas and analysis for determining the impact of energy conservation measures on buildings, processes and energy systems. This feature of simulation tools allows building energy analysis from the earliest conceptual design stages, doing comparative studies on building form, build geometry, system types, lighting etc. without building different design options and doing experimental observations [1].

Energy simulations are conducted using software tools that calculate the thermal loads and energy use of residential, commercial and industrial buildings [2-4]. Using energy simulation makes it is possible to predict the output variables of a specified model with known structure and parameters when subject to specified input variables [1, 4]. Hence, energy simulation provides an efficient method of predicting the future energy use of buildings [2]. With increase in the computational power, powerful building energy models are available for use on the personal computers and are used by a diverse group of users ranging from architects, engineers to policy makers [2, 5]. As per ASHRAE [1], energy simulation tools have the following three main components:

Input Variables: Variables that interact with the HVAC and other buildings systems (e.g., internal gain, thermostat set points and climate).

System Parameters: Parameters that define physical description of the system e.g., properties of the heating and cooling medium, insulation properties of the building envelope, thermal and mechanical efficiencies of heating and cooling plants, pumps, fans etc.

Output: Output consists of the response of the system parameters as they interact with the input variables.

\section{Choosing Right Simulation Tool}

The most important step in considering a simulation tool is matching it capabilities with project requirements [1, 6]. ASHRAE [1] and ASHRAE 140 [7] have listed factors, which are critical, in choosing a simulation tool, some of which are below:

- Sufficiently accurate to predict energy use

- Simulation tool should be compliant with ASHRAE Standard 140: Standard Method of Test for the Evaluation of Building Energy Analysis Computer Programs

- Simulation tool should be sensitive to the design option being considered

- Simulation tool should allow analyses of all options under consideration

- Simulation tool should balance the speed of analysis and the reproducibility of results

- Simulation tool should be able to perform envelope modelling

- Simulation tool should be able to model internal heat gains like peak heat rate, time variation of heat rates, latent vs. sensible heat fraction, radiant/convection split, and fraction of heat gain to space

- Simulation tool should be able to model occupant behavior

- Simulation tool should be able to model building heating, cooling and energy transfer systems

Meeting with all the above requirements and compliant with the ASHRAE Standard 140 [7], the following simulation tools are currently approved by the Canada Green Building Council (CaGBC) to perform energy simulations for Leadership in Energy and Environmental Design (LEED) certification 
JEPT 2021; 3(3), doi:10.21926/jept.2103034

[8]. These tools are widely used due to their high-resolution simulation capabilities, wide range of users, availability of reference literature and having been extensively validated:

- EE4

- eQUEST

- DOE-2

- EnergyPlus

- IES Virtual Environment

- Hourly Analysis Program (HAP)

- TRACE 700

The summary of simulation tool along with their strengths and weaknesses is provided in Table 1. 
Table 1 Comparative analysis matrix of simulation tools.

\begin{tabular}{|c|c|c|c|}
\hline $\begin{array}{l}\text { Simulation } \\
\text { Tool }\end{array}$ & Description & Strengths & Weaknesses \\
\hline EE4 & $\begin{array}{l}\text { EE4 is a DOE based energy use assessment tool } \\
\text { developed by the Natural Resources Canada for } \\
\text { validation of new building designs under National } \\
\text { Energy Code for Buildings, } 1997 \text {. }\end{array}$ & $\begin{array}{l}\text { - EE4 had been a standard tool for LEED } \\
\text { - EE4 auto generates the reference case models } \\
\text { compliant with National Energy Code for } \\
\text { Buildings, } 1997\end{array}$ & $\begin{array}{l}\text { - No compatibility with } \\
\text { OpenStudio } \\
\text { - Limited flexibility in changing } \\
\text { the system default assumptions } \\
\text { - Not updated since } 2004 \\
\text { - Being phased out }\end{array}$ \\
\hline eQUEST & $\begin{array}{l}\text { eQuest is a powerful building energy use analysis } \\
\text { tool with user friendly interface. eQuest offers } \\
\text { DOE based advanced professional-level results. } \\
\text { eQuest is a freeware tool with powerful DOE.2 } \\
\text { simulation engine. eQuest allows users to perform } \\
\text { detailed analysis of building technologies. eQuest } \\
\text { has schematic design and detailed design wizards } \\
\text { to tailor the energy analysis to suit the project } \\
\text { need. It has building creation module, an energy } \\
\text { efficiency parametric analysis module and a } \\
\text { graphical result display module. }\end{array}$ & $\begin{array}{l}\text { - eQuest has comprehensive energy analysis } \\
\text { capabilities. } \\
\text { - It allows the advanced user to input additional } \\
\text { building details to analyze complex buildings. } \\
\text { - A three-dimensional view of the building } \\
\text { geometry is available in this version. } \\
\text { - HVAC system schematic diagrams can be drawn } \\
\text { in eQuest. } \\
\text { - Well validated energy analysis tool. } \\
\text { - Used extensively in consulting and research } \\
\text { studies. }\end{array}$ & $\begin{array}{l}\text { - No compatibility with } \\
\text { OpenStudio } \\
\text { - Very limited CAD or gbXML } \\
\text { geometry import capabilities }\end{array}$ \\
\hline
\end{tabular}


DOE-2 is an hourly, whole-building energy analysis program calculating energy performance and life cycle cost of operation. Can be used to analyze energy efficiency of given designs or efficiency of new technologies. Other uses include utility

DOE-2 demand-side management and rebate programs, development and implementation of energy efficiency standards and compliance certification, and training new corps of energy-efficiency conscious building professionals in architecture and engineering schools.

EnergyPlus is a whole building energy simulation program used to model both energy consumption for heating, cooling, ventilation, lighting and plug and process loads, and water use in buildings.
- Detailed, hourly, whole-building energy analysis.

- Not been updated in two

- Allows modeling of multiple zones in buildings decades. of complex design

- Had been recognized as the standard in industry consulting and research

- Has been replaced by eQuest and EnergyPlus.

- Regularly updated

- Research oriented with advanced thermodynamically accurate simulation routines

- Seamless integration with CAD and SketchUp for easy geometrical modeling and model

- Detailed expertise is required for modeling

- Compatibility with Building Information Modeling (BIM) applications like OpenStudio 
IES-Virtual Environment is a tool for architects, engineers, draftspersons and energy analysis teams.

IES can be used test to simulate design options,

IES Virtual

Environme

nt identify best design solutions, compare energy efficient technologies, and provide comprehensive energy and emissions results to assess each design option. IES is used by LEED, ratings in Canada. IES uses an integrated design approach and is used by design professionals to model, visualize and compile detailed energy results.

Carrier's Hourly Analysis Program (HAP) is a powerful engineering heating and cooling design load estimating software. HAP offers a simpler, efficient tool for consultants to analyze system

\section{Hourly}

Analysis

Program

(HAP) design, energy simulation and design loads to help select HVAC equipment. A wide variety of HVAC systems can be analyzed, including central station air handlers, packaged rooftop units, split systems, fan coils, and water source heat pumps. HAP uses ASHRAE Transfer Function Method for calculating building heat flow and offers rigorous results.
- Advanced design and drafting capabilities

- High quality 3D geometric modeling and rendering

- Validated as per ASHRAE Standard 140

- Modular nature of architectural, electrical, mechanical, process and renewable energy system design

- HAP balances ease of use with technical sophistication. HAP has easy to use energy analysis module to provide a reliable energy use breakdown and annual energy and fuel costs

- HAP offers easy to read reports and graphs for equipment sizing and energy analysis
- Very expensive to purchase

- Relies on several default HVAC system assumptions

- Limited use in published scientific literature

- It is designed for the consulting engineers and architects

- Features such as access to the source code, often necessary in research situations, are not offered

- Relies on several default HVAC system assumptions

- Limited use in published scientific literature

- It is designed for the consulting engineers and architects

- Features such as access to the source code, often necessary in research situations, are not offered 
As a systems and services provider, we understand the challenges of designing the most efficient, lowest cost HVAC system solution. That's why we developed Trane Air Conditioning Economics, or

TRACE 700 TRACE $^{\mathrm{TM}}$-an award-winning design-and-analysis software program that helps HVAC professionals optimize the design of a building's heating, ventilating and air-conditioning system based on energy utilization and life-cycle cost.

TRNSYS includes a graphical interface, a simulation engine, and a library of components that range from various building models to standard HVAC

TRNSYS equipment to renewable energy and emerging technologies. TRNSYS also includes a method for creating new components that do not exist in the standard package
- Provides multiple features to help model for LEED

- Reset hot-water-leaving temperatures ASHRAE Standard 90.1-2004-2010 compliant equipment library

- Simulating daylighting

- Estimate cooling coil

condensate Calculate ASHRAE 62.1 with DCV based on $\mathrm{CO}_{2}$

- Reset supply-air temperatures

- Model extensive air-to-air energy recovery options

- Detailed output reports for LEED submission

- Extremely flexible for modeling a variety of energy systems in differing levels of complexity

- Supplied source code and documentation provide an easy method for users to modify or add components not in the standard library

- Web-based library of additional components and frequent downloadable updates are also available to users

- TRNSYS also interfaces with various other simulation packages
- Limited use in published scientific literature

- It is designed for the consulting engineers and architects

- Features such as access to the source code, often necessary in research situations, are not offered

- No assumptions about the building or system are made so the user must have detailed information about the building and system and enter this information into the TRNSYS interface 


\section{Comparative Analysis of Energy Simulation Tools}

Though there are several studies on the performance or validation of individual energy simulation software $[2,5,9-12]$, to date the most comprehensive comparison between different energy performance simulation programs is Crawley et al. [6].

Crawley et al. [6] has provided an exhaustive comparison on dozens of individual features of twenty major building energy simulation tools along the following criteria:

- General modeling features

- Zone loads

- Building electrical systems

- Building envelope

- Day lighting and solar

- Infiltration

- Ventilation and multi-zone airflow

- Renewable energy systems

- HVAC systems, HVAC equipment

- Environmental emission

- Economic evaluations

- Climate data availability

- Results reporting

- Validation

- User interface, links to other programs and availability

Crawley et al. [6] conclude the overwhelming superiority in terms of capabilities and features in favor of EnergyPlus. Similarly, Lasley [13], Sousa [14] and Sola et al. [15] have provided an exhaustive comparison between different modeling features of several simulation tools. Zhou et al. [16] from Lawrence Berkeley National Laboratory concluded that EnergyPlus is a powerful simulation program with the most complete component models and the most adjustable parameters among other simulation programs.

Since Crawley et al. [8], EnergyPlus has made significant advances in its simulation engine and capabilities [17]. Some of the more recent developments and features of EnergyPlus are listed below:

- Wide scale adoption by the U.S. Department of Energy

- Open-source, programmable in $\mathrm{C}++$

- Cross-platform builds (able to work on Windows and Mac)

- Enhanced urban context simulation

- Automated ASHRAE Standard 140 testing

- Most widely used engine for published research

- Preferred platform for American Institute of Architects (AIA) 2030 reporting

- Integrated, simultaneous solution of thermal zone conditions and HVAC system response that does not assume that the HVAC system can meet zone loads and can simulate unconditioned and under-conditioned spaces

- Heat balance-based solution of radiant and convective effects that produce surface temperatures thermal comfort and condensation calculations 
- Sub-hourly, user-definable time steps for interaction between thermal zones and the environment; with automatically varied time steps for interactions between thermal zones and HVAC systems. These allow EnergyPlus to model systems with fast dynamics while also trading off simulation speed for precision

- Combined heat and mass transfer model that accounts for air movement between zones

- Advanced fenestration models including controllable window blinds, electrochromic glazing, and layer-by-layer heat balances that calculate solar energy absorbed by window panes

- Illuminance and glare calculations for reporting visual comfort and driving lighting controls

- Component-based HVAC that supports both standard and novel system configurations

- Advanced HVAC and lighting control strategies and an extensible runtime scripting system for user-defined control

- Functional Mockup Interface import and export for co-simulation with other engines

- Standard summary and detailed output reports as well as user definable reports with selectable time-resolution from annual to sub-hourly, all with energy source multipliers

- Seamless integration with CAD and SketchUp for easy geometrical modeling and model importing

- Compatibility with Building Information Modeling (BIM) applications like OpenStudio.

\section{Simulation Tool Ranking in Research Publications}

Alwisy et al. [18] has summarized the impact of each simulation tool in terms of the number of publications reflecting the importance of acceptance metrics of evidence-based research conducted in the energy simulation. The summary of simulation tool rankings is provided in Table 2. As evidenced by the Alwisy et al. [18], majority of the research publications in building systems, mechanical and electrical design requirements, weather simulations and renewable power systems analysis is EnergyPlus, followed by TRNSYS.

Table 2 Simulation tool rankings in research publications.

\begin{tabular}{lllllll}
\hline $\begin{array}{l}\text { Primary } \\
\text { Systems }\end{array}$ & $\begin{array}{l}\text { Secondary } \\
\text { System }\end{array}$ & EnergyPlus & TRNSYS & DOE-2 & ESP-r & eQuest \\
\hline & Windows & 276 & 126 & 40 & 42 & 38 \\
& Doors & 17 & 18 & 2 & 1 & 2 \\
& Shading systems & 71 & 53 & 9 & 20 & 21 \\
$\begin{array}{l}\text { Building } \\
\text { system }\end{array}$ & $\begin{array}{l}\text { Walls/ Exterior } \\
\text { walls }\end{array}$ & 260 & 222 & 58 & 30 & 26 \\
& $\begin{array}{l}\text { Interior/Internal } \\
\text { walls }\end{array}$ & 56 & 33 & 16 & 12 & 2 \\
& $\begin{array}{l}\text { Roofs } \\
\text { Floors }\end{array}$ & 138 & 125 & 34 & 11 & 18 \\
& 144 & 142 & 11 & 10 & 9
\end{tabular}




\begin{tabular}{|c|c|c|c|c|c|c|}
\hline & Ceiling & 49 & 54 & 5 & 5 & 3 \\
\hline \multirow{6}{*}{$\begin{array}{l}\text { Mechanical } \\
\text { and electrical } \\
\text { requirements }\end{array}$} & HVAC systems & 252 & 156 & 34 & 9 & 31 \\
\hline & Air-changes & 12 & 15 & 3 & 5 & 0 \\
\hline & Ventilation-rate & 27 & 26 & 4 & 1 & 0 \\
\hline & $\begin{array}{l}\text { Heating set- } \\
\text { point }\end{array}$ & 45 & 41 & 1 & 5 & 2 \\
\hline & $\begin{array}{l}\text { Cooling set- } \\
\text { point }\end{array}$ & 41 & 34 & 1 & 5 & 1 \\
\hline & Lighting control & 93 & 17 & 18 & 5 & 10 \\
\hline \multirow{7}{*}{$\begin{array}{l}\text { Building } \\
\text { design }\end{array}$} & Floor area & 49 & 33 & 3 & 1 & 5 \\
\hline & Floor layout & 3 & 1 & 0 & 0 & 0 \\
\hline & Building volume & 12 & 4 & 0 & 0 & 0 \\
\hline & Floor height & 7 & 1 & 2 & 0 & 1 \\
\hline & $\begin{array}{l}\text { Building } \\
\text { orientation }\end{array}$ & 121 & 67 & 22 & 12 & 17 \\
\hline & Fenestration & 37 & 6 & 20 & 4 & 4 \\
\hline & Occupancy & 106 & 40 & 10 & 15 & 10 \\
\hline \multirow{6}{*}{$\begin{array}{l}\text { Weather } \\
\text { conditions }\end{array}$} & Weather data & 167 & 166 & 36 & 14 & 13 \\
\hline & Solar analysis & 189 & 63 & 43 & 30 & 25 \\
\hline & Insolation & 4 & 26 & 5 & 1 & 0 \\
\hline & Sky-model & 8 & 15 & 6 & 4 & 1 \\
\hline & $\begin{array}{l}\text { Day lighting } \\
\text { controls }\end{array}$ & 51 & 6 & 15 & 3 & 7 \\
\hline & $\begin{array}{l}\text { Ground heat } \\
\text { transfer }\end{array}$ & 18 & 41 & 3 & 0 & 0 \\
\hline \multirow{2}{*}{$\begin{array}{l}\text { Renewable } \\
\text { energy } \\
\text { system }\end{array}$} & Solar-thermal & 13 & 320 & 1 & 2 & 0 \\
\hline & $\begin{array}{l}\text { Collector } \\
\text { storage system }\end{array}$ & 4 & 32 & 0 & 1 & 1 \\
\hline
\end{tabular}




\begin{tabular}{|c|c|c|c|c|c|c|}
\hline & Green roof & 29 & 6 & 1 & 3 & 4 \\
\hline & Photovoltaic & 86 & 29 & 5 & 22 & 7 \\
\hline & Wind energy & 48 & 9 & 7 & 4 & 3 \\
\hline & $\begin{array}{l}\text { Geothermal } \\
\text { energy }\end{array}$ & 31 & 16 & 2 & 1 & 2 \\
\hline $\begin{array}{l}\text { Total } \\
\text { Publications }\end{array}$ & & 2464 & 1943 & 417 & 278 & 263 \\
\hline
\end{tabular}

\section{Contextualizing EnergyPus for District Scale Energy Analysis}

As per Sola et al. [19], for district scale building stock, ideal strategy is to use integrated or cosimulation tools. This is attributed to the fact that most energy simulation tools are limited to specific purposes or sub-parts of district scale analyses [19]. In addition, with the integration or coupling of different simulation tools, researchers can link outputs of one tool to the inputs of other tools to overcome the limitations of individual simulation tool. Sola et al. [19] have analyzed fifteen capabilities of district scale energy modelling tools, ranging from individual building characterization, building stock modelling to on-site energy generation, optimization analysis and time of modelling required for these energy modelling tools. Sola et al. [19] has identified numerous co-simulation computational modules using a combination of EnergyPlus with Matlab, Simulink, Radiance, Excel VBA, City-Sim, Dymola, Modelica etc. using different model exchange interfaces, e.g., Ptolemy II, Functional Mock-up Interface and OpenStudio etc. to simulate complex, multivariable models typical of the neighborhood scale built structure.

Zhao et al. [20] have explored the integration of EnergyPlus with Matlab-Simulink for predictive control of the building. Torre and Yousif [21] have investigated natural ventilation using a cosimulation using DesignBuilder and EnergyPlus. Wang et al. [22] have explored synchronization and interaction between EnergyPlus and No-MASS for complex and multi-domain simulation requirements of district or neighborhood energy systems. Nouidui et al. [23] have described the link between EnergyPlus, Modelica and Functional Mock-up Unit (FMU) to simulate a complex numerical model of shading device on window for a room model. Wang et al. [22] have studied the optimization of the occupancy-based thermostatic schedule using a co-simulation of EnergPlus and Java-based control sequence. Building Controls Virtual Test Bed (BCVTB) has been used to integrate Matlab, Modelica and Dymola with EnergyPlus to overcome limitations of EnergyPlus for complex neighborhood level building system modelling by Wetter [24]. Few other examples are Michalak [25]-EnergyPlus integrated with Matlab-Simulink, Lassandro and Di Turi [26]-envelope optimization using EnergyPlus co-simulated with DesignBuilder and ENVI-met, Booten and TabaresVelasco [27]-optimization of residential cooling strategies by co-simulating EnergyPlus with Building Energy Optimization (BEopt) and Li [28]-optimization of district heating networks by co-simulating EnergyPlus and Simulink. Singer at al. [29]-EnergyPlus co-simulated with FMU and Java Federate to improve residential energy savings and Christina and Dounis [30]-EnergyPlus co-simulated with Simulink (for HVAC controls) and TRNSYS (for HVAC plants) using BCVTB interface, Willy et al. [31]EnergyPlus co-simulated with Matlab-Simulink to improve campus-wide integrated energy 
modelling, Willy et al. [32]-MLE + used to co-simulated EnergyPlus with Simulink for energy-efficient building controls.

Hence, it has been demonstrated by several studies that EnergyPlus has a lot of potential to be integrated to different energy simulation tools for expanding its capabilities to act as a primary simulation platform for district level energy analysis.

\section{Conclusion}

This article summarizes the findings of extensive literature review and analysis and concludes that due to its prominent use in validated research publications, advanced features, flexibility to modify the source code and compliance with validation protocols like ASHRAE 140 [7], EnergyPlus is the most widely used and validated simulation tool for building energy and power systems research. A novel area of the integration of EnergyPlus to amplify its strength for multi-domain, cosimulation platform has been analyzed. It has been demonstrated that in order to overcome technical limitations faced for district, city or municipal level energy simulations EnergyPlus offers huge flexibility for integration with other simulation tools like Matlab, Simulink, Radiance, Excel VBA, City-Sim, Dymola, Modelica, Open Studio, DesignBuilder etc.

Hence, this article concludes that EnergyPlus is preferred choice for energy and power system simulation tool for building systems and is used extensively in energy research and consulting design owing to its powerful capabilities, multi-platform integration and extensive validation of its simulation algorithm.

\section{Author Contributions}

The author did all the research work of this study.

\section{Competing Interests}

The author has declared that no competing interests exist.

\section{References}

1. ASHRAE. Description 2017 ASHRAE handbook-fundamentals [Internet]. Atlanta: American Society of Heating and Air-Conditioning Engineers; 2017. Available from: https://www.ashrae.org/File\%20Library/Technical\%20Resources/ASHRAE\%20Handbook/IP F2017-IndexIX.pdf.

2. Ryan EM, Sanquist TF. Validation of building energy modeling tools under idealized and realistic conditions. Energy Build. 2012; 47: 375-382.

3. U.S. Department of Energy. About building energy modeling [Internet]. Washington: U.S. Department of Energy; 2019 [cited 2019 March 5th]. Available from: https://www.energy.gov/eere/buildings/about-building-energy-modeling.

4. Syed Ali M. Evolution of building thermal simulation methodologies. Int J Strategic Energy Environ Plann. 2020; 6.

5. Coakley D, Raftery P, Keane M. A review of methods to match building energy simulation models to measured data. Renew Sust Energ Rev. 2014; 37: 123-141.

6. Crawley DB, Hand JW, Kummert M, Griffith BT. Contrasting the capabilities of building energy 
performance simulation programs. Build Environ. 2008; 43: 661-673.

7. ASHRAE. Standard method of test for the evaluation of building energy analysis computer programs [Internet]. Atlanta: American Society of Heating and Air-Conditioning Engineers; 2017. Available from: https://www.techstreet.com/ashrae/standards/ashrae-1402017?gateway code=ashrae\&product id=2001489.

8. Canada Green Buildings Council. Approved energy simulation software for LEED Canada [Internet]. Ottawa: Canada Green Buildings Council; 2019. Available from: https://www.cagbc.org/cagbcdocs/LEED_Canada_approved_software-EN.pdf.

9. Shrestha SS, Maxwell G. Empirical validation of building energy simulation software: EnergyPlus. Proceedings of the 12th Conference of the International Building Performance Simulation Association; 2011 November 14th-16th; Sydney, Australia. Ames: lowa State University.

10. Gucyeter B. Calibration of a building energy performance simulation model via monitoring data. Proceedings of the 2018 Building Performance Analysis Conference and SimBuild co-organized by ASHRAE and IBPSA-USA; 2018 September 26th-28th; Chicago, IL, US. Eskisehir: Eskisehir Osmangazi University.

11. Monetti V, Davin E, Fabrizio E, André P, Filippi M. Calibration of building energy simulation models based on optimization: A case study. Energy Procedia. 2015; 78: 2971-2976.

12. Shrestha SS, Maxwell G. Empirical validation of building energy simulation software: EnergyPlus. Ames: lowa State University; 2006.

13. Lasley N. Comparing building modeling software to the energy record of a preexisting structure. Bowling Green: Western Kentucky University; 2017. Available from: http://digitalcommons.wku.edu/stu hon theses/690.

14. Sousa Joana. Energy simulation software for buildings: Review and comparison. Porto: Faculdade de Engenharia da Universidade do Porto; 2008.

15. Sola A, Corchero C, Salom J, Sanmarti M. Simulation tools to build urban-scale energy models: A review. Energies. 2018; 11: 3269.

16. Zhou X, Hong TZ, Yan D. Comparison of building energy modeling programs: HVAC systems. Berkeley, CA: Ernest Orlando Lawrence Berkeley National Laboratory; 2013; LBNL-6432E.

17. U.S. Department of Energy. An NREL-led project with Collaboration from LBNL and ORNL [Internet]. Washington: U.S. Department of Energy; 2018. Available from: https://www.energy.gov/sites/default/files/2018/06/f52/35513 Lee 050318-1400.pdf.

18. Alwisy A, BuHamdan S, Gül M. Evidence-based ranking of green building design factors according to leading energy modelling tools. Sustain Cities Soc. 2019; 47: 101491.

19. Sola A, Corchero C, Salom J, Sanmarti M. Multi-domain urban-scale energy modelling tools: A review. Sustain Cities Soc. 2020; 54: 101872.

20. Zhao J, Lam KP, Ydstie BE, Karaguzel OT. EnergyPlus model-based predictive control within design-build-operate energy information modelling infrastructure. J Build Perform Simul. 2015; 8: $121-134$.

21. De la Torre S, Yousif C. Evaluation of chimney stack effect in a new brewery using DesignBuilderEnergyPlus Software. Energy Procedia. 2014; 62: 230-235.

22. Wang K, Siebers PO, Robinson D. Towards generalized co-simulation of urban energy systems. Procedia Eng. 2017; 198: 366-374.

23. Nouidui TS, Wetter M, Zuo W. Functional mock-up unit import in EnergyPlus for co-simulation. Proceedings of the 13th Conference of International Building Performance Simulation 
Association; 2013 August 26th; Chambéry, France. Berkeley: Lawrence Berkeley National Lab.

24. Wetter M. Modelica-based modelling and simulation to support research and development in building energy and control systems. J Build Perform Simul. 2009; 2: 143-161.

25. Michalak P. The development and validation of the linear time varying Simulink-based model for the dynamic simulation of the thermal performance of buildings. Energy Build. 2017; 141: 333-340.

26. Lassandro P, Di Turi S. Multi-criteria and multiscale assessment of building envelope responseability to rising heat waves. Sustain Cities Soc. 2019; 51: 101755.

27. Booten C, Tabares-Velasco PC. Using EnergyPlus to simulate the dynamic response of a residential building to advanced cooling strategies. Proceedings of the 2nd International Conference on Building Energy and Environment Boulder; 2012 August 1st-4th; Boulder, CO, US. Golden: National Renewable Energy Lab.

28. Li Y. Renovation and optimization of existing district heating networks: Towards smart low carbon thermal grids. Cardiff: Cardiff University; 2018.

29. Singer J, Roth T, Wang C, Nguyen C, Lee H. EnergyPlus integration into cosimulation environment to improve home energy saving through Cyber-Physical systems development. J Energy Resour Technol. 2019; 141: 062001.

30. Anastasiadi C, Dounis Al. Co-simulation of fuzzy control in buildings and the HVAC system using BCVTB. Adv Build Energy Res. 2018; 12: 195-216.

31. Bernal W, Behl M, Nghiem TX, Mangharam R. Campus-wide integrated building energy simulation. Philadelphia: University of Pennsylvania; 2015.

32. Bernal W, Behl M, Nghiem TX, Mangharam R. MLE+: A tool for integrated design and deployment of energy efficient building controls. Proceedings of the Fourth ACM Workshop on Embedded Sensing Systems for Energy-Efficiency in Buildings; 2012 November 6th; Toronto. Toronto: Association for Computing Machinery.

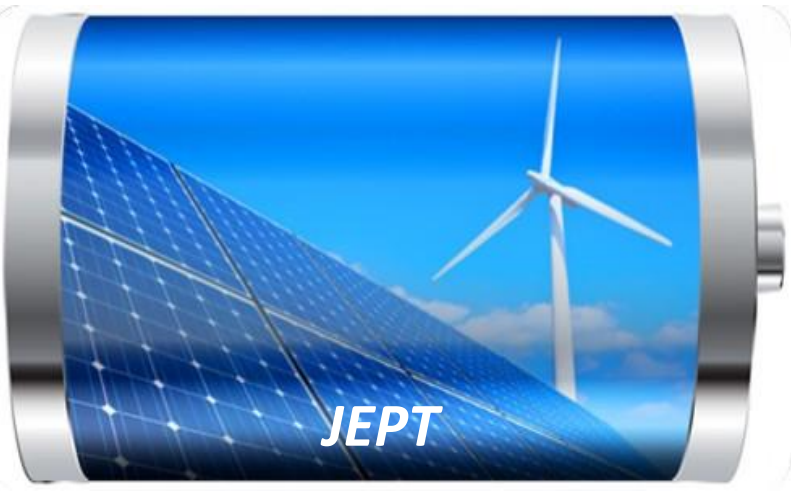

Enjoy JEPT by:

1. Submitting a manuscript

2. Joining in volunteer reviewer bank

3. Joining Editorial Board

4. Guest editing a special issue

For more details, please visit: http://www.lidsen.com/journal/jept 